\title{
La sociedad de Cervantes: un mundo conflictivo
}

\author{
María Luisa RoEL MENDIZÁBAL \\ Universidad Nacional Mayor de San Marcos
}

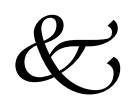

Cuando Felipe III es coronado rey de España en 1598, tiene tan solo 20 años. Atrás quedaba el gobiemo de su padre, Felipe II, conocido como "El rey Prudente". La muerte del primogénito, el príncipe Diego, en 1582, le dejó el campo libre para su ascenso al trono. La sobreprotección que entonces le brinda su padre lo lleva a rechazar los consejeros asignados por el Rey y a desarrollar una gran admiración a su abuelo, Carlos V.

Con Felipe III la nobleza castellana vuelve a asumir el poder que perdiera con el rey Prudente. Como a Felipe no le interesaba la política solía abandonarla y pasar largas temporadas dedicado a la caza y a las fiestas; es por esto que Deleito y Piñuelas lo va a llamar "el rey que se divierte". El gobiemo recaía entonces en uno de los més famosos validos o privados o favoritos, el duque de Lerma, Francisco Gómez de Sandoval y Reynas. Fra quien aconsejaba al Rey. La presencia del valido trajo consigo un incremento del gasto público al 200\% y, por supuesto, un aumento de la burocracia, que se quintuplica. En 1619 el Duque de Lerma es destituido y al poco tiempo, 1621, mere Felipe a los 43 años.

Fue una época de relativa tranquilidad. Se firma el tratado de Londres en 1604 lo que trae la paz con Inglaterra. La tregua de los doce años con las provincias unidas le ahorró a la Corona española algunos gastos. Ia paz con Francia se consigue cuando Felipe se casa, en 1615, en segundas nupcias, con Isabel. Sin enbargo, la agricultura quiebra con la expulsión de los moros en 1610-1614. Se calcula que fueron 300000 los expulsados. Cervantes habla de eso en el simpático Ricote que "llora 
por España", tierra donde nace. La población española disminuyó por la milicia, las pestes, la hambruna de 1605-1607 y los viajes a América. Contrariamente a lo que pueda creerse, la opinión pública es muy importante y respetada. No había periódicas (la Gaceta aparece en 1661) , pero aparecían publicaciones sueltas contra el gobierno y algunas autoridades, firmadas por los arbitristas quienes procedían del clero, de los funcionarios y del sector comercial. El gobiemo toleraba la crítica directa y con nombres, pero no el anonimato.

La crisis del gabiemo de Felipe III tuvo varias consecuencias en la sociedad. Una de ellas fue el aumento de los vagabundos, idealizados en la figura de los pícaros. De allí la abundancia de novelas pícaras en la época. Defomeaux (1983) nos presenta la amplia variedad de pícaros que ya existía durante el gobiemo de Felipe III. Indica que Pablo de Segovia en El buscón se encuentra con "caballeros de industria": los que de día mendigan y de noche usan ropa de señores. La mayoría de los pícaros eran estudiantes y soldados. Había un gnupo privi legiado: los ciegos, quienes tenían el monopolio de orar y vender gacetas, pliegos de cordel o almanaques.

Un grado de mendicidad lo tenían los pícaros, que tenían un trabajo pequeño y se dedicaban al hurto y al robo doméstico: los pinches de cocina y los esportill leros (los que llevan recados y roban lo que pueden). Otros pícaros son los tahúres no autorizados. En la cima de la jerarquía picaresca se encuentran los más peligrosos: ladrones profesionales y asesinos, entre los que hay hasta 12 especialidades. Una forma especial de pícaros estaba constituido por los soldados desertores o los que se quedaban sin sueldo por la pobreza de los ministerios y se veían precisados a trabajar como guardaespaldas, matones a sueldo que podían zurrar a alguien molesto.

Otro reflejo de la crisis fue la disminución de valores humanistas que dio lugar a cierto chauvinismo un poco agresivo. La prueba está en el descenso demográfico de matrículas en los estudios humanistas frente al derecho canónigo, considerado "útil".

La limitación de horizontes fue mucho mayor en los estudios científicos. A partir de los grandes índices de Gaspar de quiroga (15831584) se dio una tendencia a prohibir las obras de los autores extranjeros, aunque fueran católicos. Esta tendencia fue universal ya 
que se prohibía a un autor, pero no su obra y viceversa. La reacción contra las innovaciones de la ciencia se va a hacer sentir en la prol iferación de literatura rel igiosa que casi se triplica y en la de creación literaria que aumenta. Sin embargo, la decadencia afecta la edición y no se imprimen muchos ejemplares.

El pesimismo fue otro aspecto de la visión del mundo que tenían los barrocos. La iglesia comenzó a desempeñar un papel mucho más importante en la cultura española debido a la Contrarreforma y a su gran aliada la Compañía de Jesús. De hecho, la dirección cultural que estaba en manos de los nobles pasó a manos de la iglesia que poseía mayor capital de bienes.

"Sólo Madrid es corte". Este dicho popular reflejaba el orgullo y lo que significaba Madrid en la época. Las anteriores capitales, Toledo, Valladolid y Segovia, tenían intensa vida unbana, independiente de la corte. Madrid, en cambio, debía su fisonomía a la decisión tomada por Felipe II en 1561 de transferirle los órganos del gobiemo real. En 1606 Felipe III la consagra definitivamente como corte y villa castellana.

Madrid gozaba ya, durante el gobierno de Felipe II, de una activa vida cultural. La mayor cantidad de imprentas se encontraban allí, se convirtió en la ciudad del teatro y es allí, en 1605, que Cervantes decide publicar la primera parte de Ell ingenioso hidalgo dan Quijote de la Mancha, como una revancha al antiguo amigo y luego rival Lope de Vega, quien en 1604 pública en Sevilla (entonces lugar de residencia de Cervantes) su novela Ell Peregrino en su patria.

El inicio de una época literaria no es fácil de precisar. La crítica coincide casi totalmente en afimar que fue en 1595 cuando comienza el Barroco en España. El Barroco fue el resultado de una profunda crisis espiritual y moral desencadenada por la descomposición de la síntesis de los valores renacentistas y por la lásqueda de nuevas síntesis. Ia cosmovisión del hombre renacentista se disgrega irremediablemente. Las antítesis violentas, la tensión del alma, el sentimiento de inestabilidad de lo real, la lucha entre lo profano y sagrado, el espíritu y la came, lo mudano y lo divino son aspectos de esta crisis multiforme que ya se verificaba en Europa desde mediados del siglo XVI.

Dámaso Alonso (1962) define el Barroco como una enorme coincidentia opoositorum: arte de oposiciones dualistas, de antitesis 
violentas y exaltadas. En la literatura barroca la expresión de belleza adquiere fulgor y riqueza exuberante que la poesía petrarquesca no poseía, pero aparece también una estética de lo feo y grotesco, lo horrible y macabro.

Las escenas crueles y sangrientas abundan en la literatura y traducen una sensibilidad exasperada hasta el paroxismo; se complacen en lo horroroso y lúgubre, en la soledad y la noche. Las tensiones del barroco se expresan en las antinomias entre espíritu y came, goces celestes y placeres mundanos, fricción terrenal y renuncia ascética. Los valores sensoriales y eróticos tienen gran importancia: el mundo es conocido y gozado a través de los sentidos y los colores; perfumes, sonidos, sensaciones táctiles son fuente de deleite y voluptuosidad. Ell tema de la fugacidad, de la ilusión de la vida y de las cosas mundanas ocupa un lugar central.

Las motivaciones religiosas son evidentes: se trata de recordar al hombre que todo es vano y efímero sobre la tierra, que la vida camal es un tránsito y que es necesario buscar una realidad suprema exenta de mentiras e imperfecciones. El Barroco ama la metamorfosis y la inconstancia, tiene un agudo sentido de variaciones que secretamente alteran toda la realidad, busca el movimientoy, en el fluir universal, la esencia de las cosas y los seres. Esta temática de fugacidad e ilusión, de vida y mundo, adquiere una tensión dolorosa y un aspecto de desencanto angustioso. La metamorfosis e inconstancia se transforman en motivos de profunda y religiosa meditación y cobran significado fúnebre. Pero, por otro lado, el Barroco expresa un mundo de ostentación y suntuosidad, de gloria y magnífico aparato; traduce el gusto por la decoración rica, la luz profusa, el espectáculo fastuoso. Fue un arte de exuberancia y poder expresivo, celebra la gloria del cielo y las pompas de la tierra. El teatro es, por excelencia, la forma especial de este ideal barroco al construir un mundo imaginario donde la apariencia se afima como realidad. Las máscaras y los efectos escénicos restauran la ilusión y dejan entrever su nuptura; el espectáculo teatral se alimenta de exuberancia sensorial y la magia, de la riqueza alegórica. En el arte poético se usa un vocabulario de fuertes tensiones, de polivalencias significativas, de estnucturas complejas. Este artificio se traduce en el uso privilegiado de la metáfora, el instrumento por 
excelencia de una expresividad misteriosa, aunque se perjudica muchas veces por la tendencia hiperbólica y el gusto por la oscuridad, consecuencia de la agudeza del ingeniero. Un procedimiento estilístico característico fue la acumulación de metáforas o desarrollo de la metáfora inicial mediante una serie de nuevas metáforas. En la narrativa abundan la hipérbole, la repetición, el hipérbaton, la antítesis violenta, la construcción zeugmática de la frase (la utilización de palabras que tienen conexión en la frase y que se sobreentienden en las demás) produciendo sorpresa, concisión y dificultad. Erra un estilo usado para expresar no un pensamiento; sino un espíritu de época, el espíritu que animó a Cervantes a escribir El ingenioso hidalgo don Quijote de la Mancha.

\section{Referencias bibliográficas}

AIONSO, Dámaso (1962) : Poesía española. Fnsayos de métoobs y límites esti ísticos. Gredos. Madrid.

CÁMARAMÑ̃̃Z, Alicia (1990) : Arquitectura y sociedad en el Siglo de Oro. Idea, traza y edificio. Ediciones El Arquero, Madrid.

DEFOURNEAUX, Marcell in (1983) : La vida cotidiana en la España del siglo de Oro. Editorial Argas Vergara S.A. Madrid.

HATZFED, Helmut (1964) : Estudios sobre el barroco. Gredos. Madrid.

KAMEN, Henry (1984) : Uha sociedad conflictiva: España, 1469-1714. Al ianza Editorial. Madrid. 